\title{
KESALAHAN LOGIS PADA TEKS EKSPOSISI HORTATORI SISWA SMA N 54 JAKARTA
}

\author{
Ni Ketut Pertiwi Anggraeni \\ Program Studi Informatika, Universitas Indraprasta PGRI \\ Email: niketutpertiwi@ hotmail.com
}

\begin{abstract}
Abstrak
Kesalahan logis adalah kekeliruan yang dapat terjadi pada suatu argumen. Kesalahan logis pada teks eksposisi hortatori terjadi karena adanya argumen sebagai unsur utama dari teks ini yang tidak valid. Penelitian ini bertujuan untuk mengetahui tipe-tipe kesalahan logis yang sering muncul pada teks eksposisi hortatori yang ditulis oleh siswa SMAN 54 Jakarta. Penelitian ini mengambil kesalahan logis yang terdapat pada 70 teks yang ditulis oleh siswa kelas XI. Kesalahan logis tersebut dikelompokkan berdasarkan klasifikasi kesalahan logis dari Seyler. Hasil yang diperoleh kemudian dijabarkan menggunakan metode kualitatif dengan analisa deskriptif sebagai alat utama dalam penjabaran data. Hasil dari penelitian ini menunjukkan bahwa begging the question merupakan tipe kesalahan logis yang paling banyak ditemukan pada teks eksposisi hortatori siswa SMA N 54 Jakarta.
\end{abstract}

Kata Kunci : Kesalahan Logis, Argumen, Eksposisi Hortatori,

\begin{abstract}
Logical Fallacies are the flaws that occur within an argument. Logical fallacies on hortatory exposition text happen because it involves invalid argument as the main point of this text. This research aims to discover types of logical fallacies that mostly found in hortatory exposition text written by the students of SMA N 54 Jakarta. This research took the logical fallacies from 80 texts written by the eleventh graders. Those logical fallacies were then classified into the classification of logical fallacies by Seyler. The result obtained were described using qualitative method with descriptive analysis as the main tool in interpreting the data. The result of this research discovered that begging the question is the type of logical fallacies that mostly found in the text of hortatory exposition of SMA N 54 Jakarta students.
\end{abstract}

Key Words : Logical Fallacies, Argument, Hortatory Exposition.

\section{PENDAHULUAN}

Dalam pembelajaran Bahasa, menulis suatu karangan membutuhkan kemampuan berpikir logis yang didasari oleh pengetahuan dasar dari topik yang dibahas dalam tulisan tersebut. Maka dari itu, sangatlah penting untuk mempelajari dan menggali lebih dalam topik yang akan dibahas dalam suatu tulisan. Di dalam Standar Isi Bahasa Inggris tahun 2016 disebutkan bahwa eksposisi hortatori merupakan teks fungsional pendek yang dipelajari dalam kompetensi dasar menulis di jenjang SMA.

Tujuan dari penulisan teks eksposisi hortatori adalah untuk mempengaruhi pemikiran pembaca [1]. Pada dasarnya teks eksposisi hortatori berisikan mengenai ajakan penulis kepada pembaca untuk meyakini suatu topik atau issue yang penulis sajikan dalam tulisannya. Dalam penulisan teks eksposisi hortatori, terdapat rangka penulisan yang perlu diperhatikan, di antaranya yaitu thesis sebagai issue yang sedang dibahas, argument yang menyajikan alasan-alasan untuk memperkuat thesis, dan rekomendasi yang berisikan ajakan penulis.

Argumen memiliki peran penting yang menentukan apakah pembaca dapat setuju pada issue yang dibahas dalam teks tersebut. Namun sayangnya, seringkali siswa menemukan kesulitan dalam memberikan data untuk mengembangkan dan menguatkan issue yang sedang dibahas [2]. Pada dasarnya argumen 
menggabungkan pencarian data atau informasi dan ajakan sehingga fokus penulis terletak pada bagaimana mendapatkan data atau informasi yang tepat sehingga dapat meyakinkan pembaca [3]. Dalam suatu argumen, terdapat kesimpulan dan premis yang harus dipahami secara logis. Pada banyak kasus, argumen siswa cenderung memiliki premis yang tidak logis yang disebut sebagai kesalahan logis. Kesalahan logis terjadi dikarenakan adanya premis yang tidak mendukung kesimpulan. Hal ini terjadi karena pemilihan premis yang tidak sesuai maupun proses penyimpulan premis yang tidak tepat [4]. Kesalahan logis terbagi menjadi dua kelompok yaitu Ignoring the Issue dan Oversimplifying the Issues [5].

Ignoring the Issue adalah tipe kesalahan logis yang tejadi karena premis yang tidak relevan dengan kesimpulan sehingga memunculkan pertanyaan (begging the question) dimana kesimpulan disajikan tanpa adanya informasi atau bukti yang cukup, kemudian red herring yang muncul karena premis yang diberikan menampilkan issue yang berbeda dari kesimpulan yang diberikan, Straw Man yang kerap terjadi dengan menyerang ide lain yang berlawanan, Ad Hominem dimana premis berisikan serangan pada personal seseorang, Common Practice dimana premis mengikuti asumsi di masyarakat tanpa mengetahui asumsi tersebut benar atau tidak, serta Ad Populum yang berisikan suatu keyakinan ataupun kepercayaan.

Oversimplifying the Issues adalah tipe kesalahan logis yang terjadi karena premis yang disajikan terlalu menyederhanakan issue dan mengesampingkan bukti atau informasi pendukung lainnya. Tipe ini terdiri dari Errors Generalizing yang mana kesimpulan diambil dari menyamaratakan suatu sampel kecil, forced hypotheses yang mana premis terdiri dari bukti atau informasi yang tidak cukup kuat sehingga kesimpulan argumen terlihat seperti dipaksakan, Non Sequitur yang mana argumen berisikan celah antara kesimpulan dengan premis, Slippery Slope yang menyimpulkan argumen berdasarkan prediksi suatu kejadian. False Dilemma yang mana argumen berasal dari dua alternatif tanpa mempertimbangkan alternatif lainnya, False Analogi dimana argumen disimpulkan berdasarkan analogi yang keliru, serta Post Hoc Fallacy yang mana argumen terdiri dari hubungan premis dan kesimpulan yang kurang tepat.

Terdapat beberapa penelitian yang terkait dengan kemampuan menulis argumen dan kesalahan logis, salah satunya penelitian yang menunjukkan bahwa adanya hubungan yang signifikan antara kemampuan membaca kritis dengan kemampuan menulis argumen [6]. Penelitian selanjutnya menjabarkan bahwa strategi metakognisi dan berpikir kirtis dapat meningkatkan kemampuan menulis argumentasi [7]. Namun demikian belum banyak yang membahas mengenai kesalahan logis yang secara sadar maupun tidak sadar dibuat oleh siswa. Tujuan dari penelitian ini yaitu untuk menunjukkan kesalahan logis yang paling dominan ditemukan pada teks eksposisi hortatori siswa. Dengan menunjukkan tipe kesalahan logis, maka diharapkan guru atau pengajar dapat menentukan strategi pembelajaran untuk mengembangkan kemampuan berpikir logis pada siswa.

\section{METODE}

Penelitian ini merupakan penelitian kualitatif yang memerlukan organisasi, perhitungan, dan penjabaran data dengan analisa deskriptif sebagai alat utama dalam penjabaran data [8].

Penelitian ini dilaksanakan di SMA N 54 JAKARTA pada tahun 2014-2015. Populasi penelitian ini merupakan siswa 
kelas XI dengan sampel yang diambil sejumlah 70 teks eksposisi hortatori. Dari 70 teks tersebut, diambil kesalahan logis dan kemudian dikelompokkan ke dalam tabel kelompok kesalahan logis. Kemudian, hasil dari analisa tipe kesalahan logis dijabarkan berdasarkan kelompok kesalahan logis oleh Seyler.

Tabel 1. Analisis Kesalahan Logis

\begin{tabular}{lccc}
\hline Argumen & Premis & Kesimpulan & $\begin{array}{c}\text { Kesalahan } \\
\text { Logis }\end{array}$ \\
\hline Isi & Isi & Isi & Isi \\
Isi & Isi & Isi & Isi \\
\hline
\end{tabular}

\section{HASIL DAN PEMBAHASAN}

Hasil

Dari data 70 teks eksposisi hortatori yang diperoleh, terdapat 104 kesalahan logis, dengan rincian sebagai berikut:

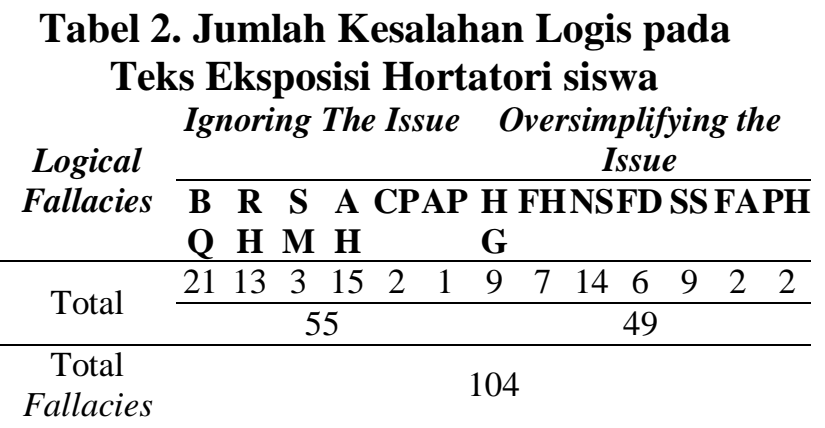

$B Q \quad$ : Begging the Question

RH : Red Herring

SM : Straw Man

AH : Ad Hominem

$C P \quad$ : Common Practice/Bandwagon

AP : Ad Populum

$H G$ : Hasty Generalization

FH : Forced Hypothesis

NS : Non Sequitur

FD : False Dilemma

SS : Slippery Slope

FA : False Analogy

PH : Post Hoc

Dari hasil klasifikasi di atas, ditemukan bahwa Ignoring the Issues merupakan tipe kesalahan logis yang sering muncul dengan banyaknya kesalahan mencapai 55 (53\%) dari 104 kesalahan. Sedangkan kesalahan logis dari Oversimplifying the issuemencapai 49 (47\%) kesalahan logis. Dengan rincian persentase masing-masing tipe sebagai berikut:

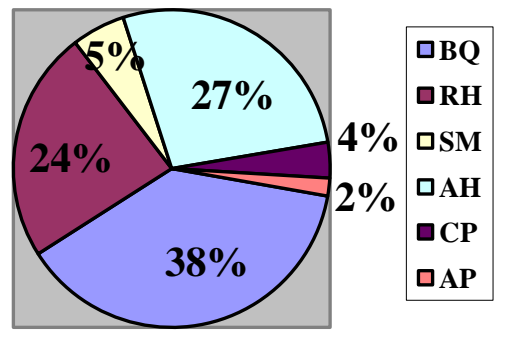

Gambar 1. Diagram Persentase Ignoring the Issue

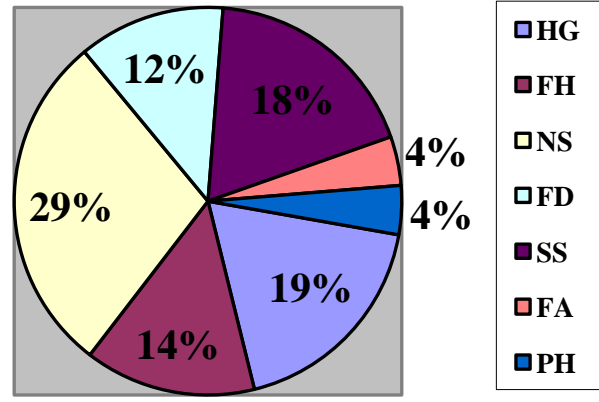

\section{Gambar 2. Diagram Persentase Oversimplifying the Issue}

Dalam Ignoring the Question, Begging the Question menjadi kesalahan logis yang paling dominan dibuat oleh siswa dengan ditemukan pada 21 argumen (38\%), lalu diikuti oleh Ad Hominem di 15 argumen (27\%), Red Herring di 13 argumen (24\%), Straw Man di 3 argumen (5\%), Common Practice di 2 argumen (4\%) dan Ad Populum hanya terdapat pada 1 argumen $(2 \%)$.

Sementara itu dalam Oversimplifying the Issue, terdapat Non Sequitur di 14 argumen (30\%), Slippery Slope di 9 argumen (18\%), Hasty Generalization di 9 argumen (18\%), Forced Hyphotheses di 7 argumen (14\%), False Dilemma di 6 argumen (12\%), False Analogy di 2 argumen (4\%), dan terakhir Post Hoc Falacy di 2 argumen (4\%). 


\section{Pembahasan}

Dari data yang diperoleh, diketahui bahwa Ignoring the Issue merupakan kesalahan logis yang paling dominan ditemukan. Hasil penelitian ini juga sejalan dengan penelitian terdahulu yang menemukan bahwa masih banyak klaim atau kesimpulan yang tidak didukung pada argumen siswa English as Foreign Language (EFL) [9]. Lebih lanjut, penelitian ini mengkerucut pada pembahasan jenis kesalahan logis yang terjadi karena kesimpulan yang tidak didukung. Masing masing tipe kesalahan logis dibahas sebagai berikut:

Begging the Question merupakan kesalahan logis yang paling dominan ditemukan di teks ekposisi hortatori siswa. Hal ini dikarenakan siswa cenderung memiliki kesulitan dalam menyajikan data dan informasi pada premis yang mendukung kesimpulan argumen. Berikut contoh sampel dari begging the question:

\section{Tabel 3. Sampel Begging the Question}

\begin{tabular}{llll}
\hline \multicolumn{1}{c}{ Argumen } & \multicolumn{1}{c}{ Premis } & \multicolumn{1}{c}{ Kesimpulan } & Kesalahan Logis \\
\hline Well, I think the measures taken so & The measures taken so & We have to prevent the & Begging the \\
far to overcome the problem by & far to overcome the & younger generations from & question \\
punishing the corruptors is still not & problem by punishing & getting a bad mentality & \\
far enough. We have to prevent the & the corruptors is still & caused by corruption & \\
younger generations from getting a & not far enough & \\
bad mentality caused by & & & \\
corruption & & & \\
\hline
\end{tabular}

Dari sampel di atas, siswa tersebut menyajikan kesimpulan bahwa langkahlangkah yang diambil sejauh ini untuk mengatasi masalah dengan menghukum korupsi masih belum cukup. Kemudian siswa tersebut memberikan premis bahwa kita perlu mencegah generasi muda dari mental buruk yang disebabkan oleh korupsi. Hubungan antara premis dan kesimpulan di atas tidak sejalan karena siswa tersebut tidak memberikan alasan mengapa langkah-langkah dengan menghukum koruptor masih belum cukup.

Ad Hominem ditemukan sebagai kesalahan logis kedua yang paling dominan ditemukan. Ad Hominem terjadi ketika siswa atau penulis menyerang personal seseorang yang tidak ada hubungannya dengan issue yang diangkat. Salah satu sampelnya adalah sebagai berikut:

Tabel 4. Sampel Ad Hominem

\begin{tabular}{llll}
\hline \multicolumn{1}{c}{ Argumen } & \multicolumn{1}{c}{ Premis } & \multicolumn{1}{c}{ Kesimpulan } & \multicolumn{1}{c}{ Kesalahan Logis } \\
\hline As most people know, tanjung priok port & Entrepreneurs who want & As most people & Ad hominem \\
smuggling is not a new thing at hall. & to minimize their tax & know, tanjung & \\
Entrepreneurs who want to minimize & payments tend to do & priok port & \\
their tax payments tend to do such a & such a thing more often. & smuggling is not a \\
thing more often. They even bribe the & They even bribe the & new thing at hall & \\
officials. & officials & & \\
\hline
\end{tabular}

Pada argumen di atas, siswa tidak memberikan data maupun bukti tambahan mengenai penyuapan di pelabuhan sehingga argumen tersebut tidak kuat dan cenderung menyerang pegawai pelabuhan.
Red Herring merupakan kesalahan logis yang terjadi karena adanya pengalihan topik yang tidak relevan dengan topik yang sedang dibahas. Berikut adalah sampel dari Red Herring: 
Tabel 5. Sampel Red Herring

\begin{tabular}{llll}
\hline \multicolumn{1}{c}{ Argumen } & \multicolumn{1}{c}{ Premis } & Kesimpulan & Kesalahan Logis \\
\hline Game online relieve stress, it turns out & it turns out the game online is & Game Online & Red Herring \\
the game online is able to be an & able to be an opportunity attempt & relieve stress & \\
opportunity attempt to make money by & to make money by sell items that & \\
sell items that exist in the game online. & exist in the game online. & \\
\hline
\end{tabular}

Kesimpulan dari argumen di atas adalah Game Online dapat melepas stress akan tetapi premis yang diberikan berupa bagaimana Game Online dapat menghasilkan uang. Common Practice atau Bandwagon terjadi ketika siswa hanya mengikuti apa yang umum dimasyarakat. Dalam argumen Common Practice, premis yang diberikan berupa pemikiran atau tindakan khalayak banyak. Berikut sampel dari Common Practice:

\section{Tabel 6. Sampel Common Practice}

\begin{tabular}{llll}
\hline \multicolumn{1}{c}{ Argumen } & \multicolumn{1}{c}{ Premis } & \multicolumn{1}{c}{ Kesimpulan } & \multicolumn{1}{c}{ Kesalahan Logis } \\
\hline We're culture not fit in to west culture & Most west culture is to & we're culture not fit & Common Practice \\
because most west culture is to free like & free like there is no rule & in to west culture & \\
there is no rule & & &
\end{tabular}

Kesimpulan di atas tidak didukung dengan premis yang menunjukkan bahwa mayoritas kebudayaan barat merupakan kebudayaan bebas tanpa adanya aturan. Pernyataan tersebut dianggap sebagai pernyataan Common Practice yang mengikuti asumsi masyarakat bahwa kebudayaan barat tidak memiliki aturan.
Straw Man terjadi ketika argumen yang diberikan menyerang pemikiran, ide, dan opini orang lain. Penyebab terjadinya kesalahan logis Straw Man dikarenakan siswa memilik pemahaman yang salah terhadap opini seseorang.

Tabel 7. Sampel Straw Man

\begin{tabular}{llll}
\hline \multicolumn{1}{c}{ Argumen } & \multicolumn{1}{c}{ Premis } & \multicolumn{1}{c}{ Kesimpulan } & \multicolumn{1}{c}{ Kesalahan Logis } \\
\hline The Government think that & But national Exam & (assumed) what Government & Straw Man \\
national Exam will make students & make a student In & thinks that national Exam will & \\
in Indonesia have a same standard & Indonesia be a & make students in Indonesia & \\
with another country. But national & cheater. & have a same standard with & \\
Exam make a student In Indonesia & & another country is wrong. & \\
be a cheater. & & & \\
\hline
\end{tabular}

Pada sampel argumen di atas, kesimpulan diasumsikan bahwa pemikiran pemerintah mengenai UN membuat siswa Indonesia memiliki standar yang sama dengan negara lain salah dengan premis yang tidak valid berupa UN membuat siswa menjadi pencontek. Ad Populum terjadi ketika argumen mengandung suatu kepercayaan atau keyakinan untuk meyakinkan orang lain. Berikut sampel kesalahan logis $A d$ Populum.

Tabel 8. Sampel Ad Populum

\begin{tabular}{llll}
\hline \multicolumn{1}{c}{ Argumen } & \multicolumn{1}{c}{ Premis } & Kesimpulan & Kesalahan Logis \\
\hline In certain religion, Democracy is not & Let uneducated people & In certain & Ad populum \\
proper in country. Let uneducated & choose the leader is bad. & religion, & \\
people choose the leader is bad. & Because uneducated people & Democracy is & \\
Because uneducated people do not know & do not know exactly the & not proper in & \\
exactly the profile of the leader. & profile of the leader. & country. & \\
\hline
\end{tabular}


Argumen di atas mengandung kesalahan logis karena mengandung kepercayaan suatu agama sementara premis tersebut dianggap tidak relevan jika mengkaitkan agama dengan demokrasi pada suatu negara.
Non Sequitur terjadi ketika premis yang diberikan tidak sejalan dengan argumen bahkan cenderung bertentangan ataupun memiliki jarak. Sampel dari Non Sequitur berupa:

Tabel 9. Sampel Non Sequitur

\begin{tabular}{llll}
\hline \multicolumn{1}{c}{ Argumen } & \multicolumn{1}{c}{ Premis } & Kesimpulan & \multicolumn{1}{c}{$\begin{array}{l}\text { Kesalahan } \\
\text { Logis }\end{array}$} \\
\hline $\begin{array}{l}\text { Seen from the name, fast food is definitely } \\
\text { presenting very fast. So many benefits for }\end{array}$ & $\begin{array}{l}\text { So many benefits for us to } \\
\text { save time. Presentation is }\end{array}$ & $\begin{array}{l}\text { Seen from the } \\
\text { name, Fast food }\end{array}$ & Non Sequitur \\
us to save time. Presentation is practical & $\begin{array}{l}\text { practical and can make us } \\
\text { and can make us bothered while working }\end{array}$ & $\begin{array}{l}\text { bothered while working } \\
\text { anesenting very }\end{array}$ & $\begin{array}{l}\text { presenting } \\
\text { another job. }\end{array}$ \\
\hline
\end{tabular}

Argumen di atas memiliki kesimpulan bahwa makanan cepat saji disajikan sangat cepat. Namun premis yang diberikan bertentangan dengan menyatakan bahwa penyajiannya sangat praktis dan dapat menggangu kita dalam mengerjakan pekerjaan lain.
Hasty Generalization merupakan kesalahan logis yang terjadi ketika penulis hanya mengambil data-data yang sedikit untuk menarik kesimpulan.

Tabel 10. Sampel Hasty Generalization

\begin{tabular}{llll}
\hline \multicolumn{1}{c}{ Argumen } & \multicolumn{1}{c}{ Premis } & \multicolumn{1}{c}{ Kesimpulan } & \multicolumn{1}{c}{ Kesalahan Logis } \\
\hline Different situation in school and & At course, is only one till 30 & Students at & Hasty Generalizing \\
course. At course, is only one till 30 & students at class. The & course are easy & \\
students at class. The teachers are & teachers are younger than at & to ask the & \\
younger than at school, so close to & school, so close to them and & teacher. \\
them and easy to ask. & easy to ask. & & \\
\hline
\end{tabular}

Argumen di atas menarik kesimpulan dari menyamaratakan guru di tempat kursus lebih muda dibanding di sekolah. Untuk menghindari argumen yang hasty generalization, siswa dapat menggunakan kualifikasi nomina seperti beberapa, banyak, sedikit, dll,
Slippery Slope terjadi saat kesimpulan yang ditarik berdasarkan prediksi dari suatu kejadian atau fenomena dan tidak memperhatikan kemungkinan-

Tabel 11. Sampel Slippery Slope

\begin{tabular}{llll}
\hline \multicolumn{1}{c}{ Argumen } & \multicolumn{1}{c}{ Premis } & Kesimpulan & Kesalahan Logis \\
\hline Online Game makes you forget about & It makes you less communicate & Online Game & Slippery slope. \\
real world. It makes you less & with your friend in real world & makes you & \\
communicate with your friend in real & and it will make you to be an & forget about & \\
world and it will make you to be an & anti social & real world & \\
anti social & & & \\
\hline
\end{tabular}

Pada argumen di atas, terlihat bahwa siswa memprediksi apa yang akan terjadi jika terlalu lama bermain game online. Argumen tersebut menyatakan bahwa siswa akan menjadi anti sosial jika mereka bermain game online yang dimana prediksi tersebut bisa keliru. 
Forced Hyphoteses merupakan kesalahan logis yang berasal dari membuat hipotesa tanpa bukti atau informasi yang kuat. Berikut contoh Forced Hyphoteses:

Tabel 12. Sampel Forced Hypotheses

\begin{tabular}{llll}
\hline \multicolumn{1}{c}{ Argumen } & \multicolumn{1}{c}{ Premis } & Kesimpulan & Kesalahan Logis \\
\hline We don't need to live in boarding & because our home far from school, & We don't & Forced hypotheses \\
house because our home far from & so we can get our parent's love & need to live & \\
school, so we can get our parent's & and their attention for us also we & in boarding & \\
love and their attention for us also we & can get the parent's control. We & house & \\
can get the parent's control. We can & can study relaxly and maximal in & \\
study relaxly and maximal in & competition to get the & \\
competition to get the achievement. & achievement. And we can save our & \\
And we can save our energy. & energy. & \\
\hline
\end{tabular}

Dalam kesimpulan di atas, yang berupa siswa tidak perlu tinggal di kos, dihipotesiskan karena kasih sayang dan perhatian dari orang tua lebih mudah didapat jika kita tinggal bersama mereka. Alasan tersebut tidak memadai dan cenderung dipaksakan karena siswa yang tinggal di asrama juga bisa mendapatkan cinta dan perhatian orang tua.

False Dillema terjadi jika argumen berisikan asumsi dari 2 pilihan yang ada tanpa melihat pilihan lain. Contoh False Dillema sebagai berikut:

Tabel 13. Sampel False Dilemma

\begin{tabular}{llll}
\hline \multicolumn{1}{c}{ Argumen } & \multicolumn{1}{c}{ Premis } & \multicolumn{1}{c}{ Kesimpulan } & \multicolumn{1}{c}{ Kesalahan Logis } \\
\hline $\begin{array}{l}\text { Show them that you don't hate them } \\
\text { back although you know what they did } \\
\text { to you, because when you hate them } \\
\text { back, it means you agree about what } \\
\text { they said. }\end{array}$ & $\begin{array}{l}\text { when you hate them } \\
\text { back, it means you } \\
\text { agree about what they } \\
\text { said }\end{array}$ & $\begin{array}{l}\text { Show them that you } \\
\text { don't hathe them back }\end{array}$ & False Dilemman know \\
what they did to you & \\
& & & \\
\hline
\end{tabular}

Argumen di atas hanya memberikan 2 pilihan yang berupa jika membenci maka setuju, jika tidak membenci maka tidak setuju. Hal ini dianggap kesalahan logis karena argumen tersebut tidak memperhatikan pilihan-pilihan lain dari alasan mengapa kita tidak membenci mereka.
Post Hoc Fallacy ditemukan pada 2 argumen siswa, kesalahan logis ini terjadi ketika penulis membuat kesimpulan dengan sebab akibatyang keliru. Berikut contoh Post Hoc:

Tabel 14. Sampel Post Hoc Fallacy

\begin{tabular}{llll}
\hline \multicolumn{1}{c}{ Argumen } & \multicolumn{1}{c}{ Premis } & \multicolumn{1}{c}{ Kesimpulan } & Kesalahan Logis \\
\hline $\begin{array}{l}\text { Our country got the benefits from the } \\
\text { products. so I suggest you to still consume }\end{array}$ & $\begin{array}{l}\text { our country got the } \\
\text { benefits from the }\end{array}$ & $\begin{array}{l}\text { I suggest you to still } \\
\text { consume fastfood for }\end{array}$ & Post hoc fallacy \\
& & $\begin{array}{l}\text { helping our country's } \\
\text { income }\end{array}$ & \\
\hline
\end{tabular}

Argumen di atas menyarankan pembaca untuk tetap konsumsi Fast Food untuk meningkatkan pendapatan negara. Hal ini menjadi keliru karena untuk mendukung pendapatan negara tidak hanya dengan konsumsi fast food.
False Analogy terjadi ketika argumen mengandung analogi yang keliru seperti analogi yang disajikan tidak sesuai dengan topik yang dibahas. 
Tabel 15. Sampel False Analogy

\begin{tabular}{llll}
\hline \multicolumn{1}{c}{ Argumen } & \multicolumn{1}{c}{ Premis } & \multicolumn{1}{c}{ Kesimpulan } & Kesalahan Logis \\
\hline $\begin{array}{l}\text { And the horrible disease ever is "be } \\
\text { a not smart person" We know this }\end{array}$ & Weed brilliant person and not & And the horrible & False Analogy \\
globalisasi era need brilliant person ever is & smart people just like a little & "be a not smart \\
$\begin{array}{l}\text { and not smart people just like a little } \\
\text { rubish }\end{array}$ & rubbish & person" & \\
\hline
\end{tabular}

Dalam argumen di atas, orang pintar dianalogikan seperti sampah. Hal ini tentunya sangatlah tidak pantas dan tidak sesuai. Makna orang pintar dianggap sebagai sesuatu yang positif sehingga analogi yang sesuai adalah sesuatuyang memiliki nilai positif.

\section{SIMPULAN}

Berdasarkan pembahasan hasil analisa, dapat disimpulkan bahwa Begging the Question merupakan kesalahan logis yang paling dominan ditemukan di teks eksposisi hortatori siswa. Kesalahan logis ini terjadi ketika siswa tidak dapat menyajikan data dan informasi valid pada premis untuk mendukung kesimpulan argumen. Maka dari itu, sangatlah penting untuk mencari informasi sebanyak mungkin terkait topik yang akan dibahas agar dapat menghasilkan argumen yang valid dan terpercaya. Mengingat pentingnya kemampuan berpikir logis pada kompetensi menulis, maka perlu adanya penelitian lanjutan mengenai strategi mengembangkan kemampuan berpikir logis siswa.

\section{DAFTAR PUSTAKA}

[1] V. Kurniawan and Fitrawati. "Teaching Hortatory Exposition by Using Stop and Dare Strategy to Senior High School Students". JELT, vol. 3, pp. 159-167, 2014.

[2] M. Geraldine. "The Effectiveness of Four Corners Strategy in Teaching Writing Hortatory Exposition Text”. Int. J. Multi Disipline Sci., vol. 1,no.
2, pp. 95-103, 2018. doi: http://dx.doi.org/10.26737/ijmds.v1i1.425 International.

[3] J. D. Ramage, J. C. Bean, and J. Johnson. Writing Arguments, A Rhetoric with Readings, 10th ed. USA: Pearson, 2010.

[4] D. S. Istiningdias dan G. Argenti. "Logical Fallacy dalam Narasi Media CNN Indonesia 'Pemerintahan Boneka di Era Jokowi-JK"'. AKRAB JUARA, vol. 4, no. 4, pp. 28-42, $2019 . \quad$ doi: 10.1017/CBO9781107415324.004.

[5] D. U. Seyler. Read, Reason, Write, 5th ed. Boston: Mc-Graw Hill, 1999.

[6] Y. S. Utami, E. Ratna, dan C. Wirsal. "Hubungan Kemampuan Membaca Kritis dengan Kemampuan Menulis Argumentasi Siswa Kelas XISMAN 1 Kinali”. Jurnal Pendidikan Bahasa dan Sastra Indonesia,vol. 1, no. 1pp. 139-144, 2012.

[7] I. Nurmahanani. "Penerapan Strategi Metakognisi dan Berpikir Kritis dalam Menulis Argumentasi pada Mahasiswa PGSD UPI Kampus Purwakarta". Metod. Didakt., vol. 10, no. 1, pp. 57-68, 2015. doi: https://doi.org/10.17509/md.v10i1.32 42.

[8] L. Cowen, L. Manion, and K. Morrison. Research methods in education, 6th ed., vol. 38, no. 3 . USA: Routledge, 2007.

[9] N. Alagozlu. "Critical Thinking and Voice in EFL Writing". Asian EFL J., vol. 9, no. 3, pp. 118-136, 2007. 